\title{
Define Your Terms! Dictionaries, Medievals, and Thinking about Concepts
}

\author{
Darius M. Rejali, Reed College
}

\begin{abstract}
A good grasp of concepts is essential in every area of political science, not just in political theory. In what follows, I describe one pedagogical strategy I use to help students learn to define the concepts they work with. This strategy involves compiling a dictionary of key political concepts over the course of a semester. Encouraging students to compile a dictionary of concepts may prove to be a more helpful and flexible way of integrating course readings than a paper or an exam. Learning to compile a dictionary might serve as a supplement to covering key debates in a subfield, as a way of reinforcing a literature review, as a way of reflecting on the changing priorities of researchers, as an introduction to different methodological perspectives, or as a means of tracing the formation of a subfield. Here are some ways a dictionary can be adapted to a variety of standard courses in political science:
\end{abstract}

- Concepts are sometimes at the heart of major debates, as the concepts of "the state" and "revolution" are in comparative politics. Although the literature in this area is enormous, the concepts themselves are fairly easy to trace. Students can pick up the thread of a concept as it unravels in different texts; the definitions themselves will bear in miniature the traces of major theoretical debates.

- In other cases, concepts have not become the focus of disciplinary debate but have, in any case, undergone hidden and subtle reconsiderations in a short period. Tracing the multiple definitions of "regime" in international politics is almost the same as conducting a literature review.

- A particular concept may no longer have as broad a currency as it used to. "Political corruption," for example, seems to have been the focus of fairly intense debate in the late 1960 s in the study of devel- oping countries, but interest in this topic has waned, even if it has waxed in the study of American politics. Students may consider then why research priorities changed and what makes a concept wax and wane.

- New concepts have entered into the study of politics. "Gender," for example may have had conceptual antecedents in several other terms, but brings with it a distinct set of methodological commitments in the study of politics that older terms do not have. What are these commitments and are they compatible with typical behavioral approaches? If not, why not?

- "Child abuse" illustrates a distinctly different turn a concept can take in a field, in this case, policy analysis. Today's concept of child abuse covers an entirely different range of acts than the term did 30 years ago and this internal transformation brought with it an explosion of policy literature on child abuse between 1965 and 1980 . What does this tell one about the relationship of conceptual change to social science and policy decision-making?

The dictionary project then can be adapted to a variety of different courses. I particularly enjoyed using this project as a way to think about medieval political theory, and I will lay out its advantages in that context as an example of how a dictionary project might unfold.

\section{The Concept of a Concept}

I turned to the dictionary project because I repeatedly encountered a familiar problem, one that I suspect is much more common than many imagine. Many student papers are hampered by conceptual confusions, and I often have to explain to puzzled students why a particular argument failed because of a poor conceptual understanding. "Look here, you needed to define your terms better here," I say, and the student nods knowingly. Yet what seems to be a tacit understanding may in fact disguise a chasm between the student and me. What the student thinks is involved in "defining" a "concept" may not be anything close to what I understand, while I may miss the opportunity to aid the student to make up for this deficiency. Inevitably, this situation ends with the same confusions appearing in the second paper. Once again, I discuss what defining concepts means, but now the frustrated student responds, "But in my second paper I did exactly as you said!’ Well, not quite.

Thinking about concepts is a complex task, and the lessons students must learn are not easy ones. ${ }^{1}$ One lesson is that concepts are not nonlinguistic entities we grasp with our minds. Rather, we need to pay attention to the words used to express a concept and the contexts in which these words are used. In clarifying the context (e.g., by examining what arguments are made and what authorities are invoked) we learn a great deal, perhaps, according to some, all there is to learn about a concept.

A student must learn next what seems like quite the opposite lesson; that concepts and words are not identical. For words may mean different things, and the same words may come to express different concepts. We know this has occurred in texts we are reading because the different authors use the same words to do different things. As the context in which the words are located changes, new concepts emerge.

Students must learn as well that there can be ruptures and mutations in political science, and that concepts have a history. Many of our conceptual confusions are explained by learning what we have forgotten about a concept's history. Like geological strata, the layers of 
meaning in a concept are confused, perhaps because they are often associated with great and highly contested human projects passed on from generation to generation.

So when I ask a student, "Do you understand concept X?" I may be calling on very different intellectual habits. I may be asking, do you know how to use this concept in an argument? do you know what this word does in this text? do you know the conceptual confusions hidden in this concept? or, do you realize that this word changes meanings in these two texts? Asking how familiar a student is with a concept is much like asking someone how well they know Rome. No one can know Rome in its entirety, but they possess different kinds of savoir faire or know-how for getting around the city. In the city of political science, mastering a concept may call on different kinds of knowledge and require students to master very different kinds of skills.

\section{The Dictionary Project}

Now let me make a more controversial claim, that there is no easy place within a political science curriculum where "defining and using a concept in a sentence" can be learned well. A moment's reflection will make clear why that is so. Supposedly, students can master conceptual thinking by watching how the teacher does it (in lecture or conference), writing arguments, and reading carefully. Each of these however has crucial weaknesses. The way a good teacher clarifies conceptual confusion might be enthralling, but it is not a substitute for learning. Students may be able to imagine how one works with a concept; this does not mean they can do it without practice. Working with concepts involves know-how, not just knowledge. One can learn about concepts by trying to figure out what's wrong with one's argument, but this approach leaves developing a good conceptual eye to chance. Sadly, often students come upon their conceptual confusions after the argument has been written and forgotten. As for careful reading, I fear we teach students the opposite habit. Given the extensive reading teachers often assign, students learn quickly that what matters is the "main idea." Scanning the reading is taken to be the same thing as reading it.

This is not to take away from the strengths of these kinds of exercises. Political scientists must speak well, criticize effectively, write logically, and synthesize extensive readings clearly. But none of these exercises is suited to mastering concepts, yet they all presuppose them. So I want to turn to the dictionary project now and explain why I think it is well suited to this task. Let me discuss first its basic elements.

1. Format. The basic dictionary entry resembled the Oxford English Dictionary format. Each entry included main definitions as well as subsidiary meanings, and each meaning was illustrated with a quotation from the required texts. Quotations included author, text, date of the text, and page number to the standard editions we used. To recognize the key word, I asked that the word be shortened to its first letter capitalized. A standard weekly submission looked like this:

\section{Tranquility (Tranquilitas)}

(A) the absence of conflict 1519 Machiavelli (Discourses, p. 299): Rome was aiming at empire and glory, not at $\mathrm{T}$.

(B) harmony or agreement of parts 1324 Marsilius (Defensor Pacis, p. 90) For $T$ was the good disposition of the city or state, whereby each of its parts can perform the functions appropriate to it in accordance with reason and its establishment.

2. Writing. Students wrote the dictionary in two stages. At first, each student submitted six short sentences (or adaptations of previous entries) a week based on the readings assigned for that week. I reviewed and returned these, with brief comments and suggestions. In five weeks, my twenty students had produced 600 definitions, and this material constituted the raw material for the dictionary. Because 600 definitions is ample in my experi- ence, the larger the class, the fewer the required weekly entries.

The next stage was to edit this material because the students had often duplicated each other's work, used the same quotation to illustrate different meanings, and improved their ability to define concepts with time and familiarity with the readings. So I created four editorial groups of about four to five students each and assigned each to a portion of the dictionary (A-G, for example). I asked them first to eliminate one-third of all the entries in their section in one week. Students found this the hardest part, but their teamwork here enabled them to work better on the next task: to discuss, pare down, and consolidate various definitions into one clear, well-developed entry.

Each group submitted their section at the end of the semester, and we appended these to make the dictionary. The final dictionary was about 80 pages long with about 100 entries. Each group section was about 20 pages. In addition to the entries, students often had provided commentaries on a definition and included cross-references to other concepts in the dictionary in the manner of a philosophical glossary (See attachment).

3. Teaching Aids. I provided several aids to help the students with their work. I provided a centralized computer file in which students could deposit their definitions anonymously. So while I read and commented on their submissions individually, students could learn from each other. In the editorial stage, students also were able to edit entries more quickly. Yet the computer is not indispensable for such a project; a central log or file might work just as well. What is important is that the teacher safeguard the anonymity of the entries so that paring the definitions later does not become a matter of personal pride.

On the first day, I also provided students with some "ideal" dictionary entries, standardized reference forms for the main texts we read, and a list of concepts they might want to keep an eye out for while they were reading. I also provided some "compilation rules" which cautioned students against the most 
common errors. These rules included the following.

1. Definitions must be concise. No proper nouns are acceptable. Phrases (e.g., just war) may be used only if prior entries exist for "war" and "justice."

2. Quotations must be complete sentences (no chapter headings). They have to come from the approved texts, not secondary sources.

3. In defining a noun (e.g., peace), make sure the sentence also uses the concept as a noun (e.g., not peacefulness, peacefully, or peaceably).

4. Make sure the quotation matches the meaning being identified for this concept. (Careless reading of a sentence was without doubt a major problem.)

5. Do not define a word by what it is not unless it is absolutely necessary.

6. Do not parrot a quotation as a definition unless it is absolutely necessary. If the sentence says, "Virtue is the sweet reward of effort," do not define virtue as "the reward of effort." This entry tells us about causation perhaps, but not what virtue is.

Further, I set aside a few classes toward the end of the semester for editorial work. While different groups worked on different sections, I moved from group to group, fielding questions and discussing problems. I also arranged a brief tour of the library reference section, introducing students to the main dictionaries and encyclopedias they could use in doing their editing.

4. Grading. I based the final grade on the weekly definitions each student submitted in the first six weeks, the final edited section of the dictionary each group produced, and a required group evaluation submitted by each student at the end of the course and class participation in the course more generally. Grading is an onerous business, yet I found grading these class assignments much more interesting than grading the usual papers and exams. Aside from the novelty of the design, I found grading to be a genuine educational experience. I learned a great deal as I tried to figure out where a student went wrong or right. I was forced to deal with sentences I had never noticed before as well as translations that left a great deal to be desired. Teachers often say how much they learn from their students; the great advantage of the dictionary is that your students teach you whether they know it or not.

Let me turn to the grading details. I graded the weekly definitions on a scale of 1 to 5 points. (1) indicated that the student defined the concept thoughtlessly, i.e., the student did not wonder whether the word was important in political thought or at the very least in our class discussion, and put no effort into finding an adequate quotation to illustrate the point. (2) indicated that the student had defined and illustrated the concept roughly within the rules, i.e., good choice of definition, but the quotation did not pertain to the definition. (3) indicated that the student had defined and illustrated the point within the rules I specified for compilation. (4 or 5) indicated that the student had gone beyond this, choosing major concepts and quotations of significance or perhaps compiled more than one sense of the concept. I should add that, as is traditional at Reed College, my students never received grades on their assignments. Instead of numbers, I designated the major problem with the submission "lack of agreement," "parroting the quotation," "Why is this a significant concept?" "redundant phrasing," or "too many equivocations in the definition." This helped students identify the particular problem they had in defining and using concepts weekly.

I used several criteria to evaluate each section of the dictionary. These included whether the students defined the concept parsimoniously, whether they precisely defined the different senses of the concept, whether the quotations illustrating the meaning were clear and in agreement with the sense in question, and whether the terms and quotations discussed were significant and based on our class work. Often students provided commentary on their definition, citing research that they had done in the reference section of the library. While this was not necessary, I did consider this in assigning the overall grade.

Because students worked in groups on their own, I also asked them to complete a group evaluation form. The form asked for the following information:

1. Describe the group process: who did what, when, where and how? Include the chores (like formatting) as well as the intellectual work. (If you prefer you may answer 2 instead.)

2. Answer these with one or two names at most.

Who was the most punctual in the group (always got the work done on time, always there, etc.)?

Who was the most attentive to other people's concerns, questions, and anxieties?

Who argued most persuasively in your group?

Who raised the important intellectual questions?

Who answered the important intellectual questions?

Who asked the important questions about procedure (how to do something)?

Who answered these questions? Who referred a lot to what the actual texts said?

Who had read closely what you wrote?

Who listened to what you said best?

Who had the most spontaneous and interesting ideas?

Who was the most pragmatic?

Who referred a great deal to sources outside of class? Which ones?

Who provided good criticisms of your work?

Who talked to you about the group project outside of group meetings?

Who was an expert in a particular field and used that expertise? Who was the most flexible and cooperative person in the group? Whose opinions did you trust the most? Why?

Whose performance surprised you the most in the group? 
Who behaved differently in the small group? Why did this impress you?

\section{Adapting the Dictionary to Your Own Purposes}

Every teacher uses assignments to achieve overall course objectives. My objectives in teaching medieval political theory were more than teaching students the skill of defining a concept. I hoped to breathe life into the way students read medieval tomes like Marsilius' Defensor pacis or Aquinas' Summa theologiae. I wanted to introduce the students to families of concepts; in this case, the relation between Christian and Greek concepts in medieval texts. I hoped that by examining different senses of concepts they would notice fissures and tensions in the texts, as well as the way authors tried to bring coherence to a complex intellectual inheritance.

Let me discuss these ideas a bit more. Medieval political theory is the least-offered course in a theory curriculum. The reasons are not surprising. With Hobbes and Locke, we have characteristically modern problems; students have no difficulty recognizing their relevance. Study of the ancient Greeks lacks this visceral advantage, yet the Platonic dialogues are wonderful to read. While Aristotle has some controversial views, they are views that can be usefully questioned. Students find Aristotle and Plato comfortably secular thinkers and give them their due as foundational thinkers in the Western tradition.

But a teacher who sets out to introduce medieval political theory cannot depend on any of these supports. Medieval texts are odd, ponderous books. Their shape and structure cannot compare to the elegance of Platonic dialogue. Their subject matter seems to have little relevance to modern political problems and is often grounded in historically obscure contexts. Finally, medieval theory suffers from a jumble of Christian and Greek thought, the latter too faint to command attention and the former so strong as to make students demand to know why they are reading political theology. To these obstacles, I must add requirements I place upon myself as a teacher. I prefer, wherever possible, to use original texts rather than secondary readings or anthologies (which are, after all, scholarly arguments in another form). I prefer as well to avoid lecturing and to encourage interaction between students. And finally, I prefer students not only to understand medieval political theory but also to reinforce a key skill. Students may forget what Aquinas said or how Christine de Pisan responded, but I hope they pick up a key disposition that will help them in their other courses.

To this end, I chose to teach my course as a combination of lectures, conferences, and the dictionary. I devoted two hours a week to student conferences and one hour a week to either lectures or the dictionary editing groups once they got started. The lectures introduced students to the texts, sometimes providing historical or philosophical background. The dictionary provided the focus for the small discussion groups. In the dictionary, the students found a precise task that did not require constant facilitation on my part. The lecture or editing days were followed by the conferences in which I facilitated the students through assigned readings.

\section{Evaluating the Project}

Student evaluations of the class were extremely positive. Almost every evaluation appreciated the balance of lectures, conferences, and small groups. As students quickly found out, paying attention to a single concept and looking for a good illustrative quotation can alter how one understands a text, how one reads, and how one engages another student in class. Arguments in class improved as students' conceptual eye improved. As we proceeded chronologically, students began recognizing differences in the way words were used and how concepts changed significantly from author to author. One student observed that if she ran across the same word in another class on a different subject, she could not help wondering what this indicated about how the concept had changed and developed. In other words, what had begun as a skill had now become an intellectual habit for her that she could not turn off at will, and one that many a teacher would recognize as a virtue.

With regard to the dictionary, students described writing it as "a unique experience." On the negative side, students thought the effort was "a little overambitious" for undergraduates. On the positive side, students appreciated the notion of an "ongoing assignment" that provided "a nice sense of continuity" to the class. As one student remarked, "I quite enjoyed working on the dictionary, using it as a conceptual sounding board."

What I found more interesting in the student testimonials was that even the critical comments on the class reflected the influence of the dictionary project. Some wanted to explore certain tensions they saw among natural law thinkers more clearly (especially Ockham and Aquinas), and insisted that I eject Marsilius or some other text to this end. Another remarked, "Quite honestly, I wish we could have had the time to do a final paper. For me, it would have meant coming to a very thorough understanding of the relationship between medieval concepts. Editing was helpful in this, but not as much as the paper would have been. Perhaps you can have the next class work off of our dictionary as to eliminate the time spent on finding quotes." This is a good idea for the next class now that the dictionary exists; the final dictionary is not without its faults. A paper would no doubt have served the purpose of capping the dictionary project, providing focus now that the students also had depth and breadth. Although I think many students would have appreciated this focus, doing two major projects would probably have meant doing both poorly. What I think is especially important here is this: I wonder if the topic on which the student wants to 
write here would even have been imaginable had the student not gone through the dictionary project.

Setting aside the student testimonials, I found class discussion was richer, if not also more chaotic and imaginative. Reading medieval texts became like detective work in which quotations were suspects and concepts were seized upon with enthusiasm. As the contours of a concept, and its possible usages, became apparent, students found they could identify more clearly the philosophical problem to be discussed and solved in a text. They also found that the Christian and Greek senses of concepts gave them windows onto what they knew of Plato and Aristotle as well as onto later conceptual confusions that emerged in modern political thought; the jumble of usages became a source of strength rather than confusion. All of this was done, as I had hoped, through a syllabus composed solely of medieval texts.

In most courses, a teacher uses the apparatus of scholarship to educate students. In this class, I handed over the apparatus of scholarship to the students so that they could educate themselves. What they discovered once they learned the skills necessary is what we all learn about real research, namely, that the focus of our research has to come from us, not from our teachers. No doubt, assigning papers and exams can serve to teach students about the finer points of Aquinas or Marsilius; the dictionary project is no substitute for this kind of craftsmanlike detail. These assignments, however, cannot substitute for the genuine confidence students need to get on with their lives. The dictionary project resembles a scaffolding that, once its lessons have been internalized, can be dispensed with as students move on to their own intellectual projects.

\section{Postscript}

Since writing this essay in the spring of 1993, I have used the dictionary project in other classes, and it might be helpful to indicate how
I have adapted it. I most typically use the dictionary in my class on the philosophy of social sciences, a course that reviews the debates around scientific status of the social sciences. I administer a midterm exam and then offer the students a choice as to their final project: a paper or a dictionary. I provide the students with a very long list of possible words to consider for a dictionary and ask that they work with $40 \%$ of the list. The list has several columns including one for words pertaining to "truth," "desire," and "power." This list mitigates the need for editorial groups because it delimits the field of words. I emphasize to students choosing the dictionary option that they should select a theme around which to organize the dictionary. This is especially important in the philosophy of social sciences because not only are concepts contested, but so are the criteria for using them properly. I've received dictionaries on schools (e.g., a dictionary of behavioralism or structuralism) and on conceptual controversies (e.g., a dictionary on "power and agency" or "a feminist dictionary for the social sciences'). I still encourage students to work in groups, but many do work on their own thematic interest.

Roughly half the students each year choose to do the dictionary rather than the paper. To enter into their senior year, all political science majors must pass a junior qualifying examination, and one third of the exam is based on this course on the social sciences. The seniors report that the dictionary was just as helpful as a paper in helping them synthesize material for the exam. In their study groups for the exam, students who did the dictionary complemented the students who wrote papers, the former raising the conceptual distinctions and the latter presenting the arguments.

\section{From The Final Dictionary}

\section{Dominion}

(A) Control over others 425 AUGUSTINE (CG, p. 868-9) For pride hates a fel- lowship of equality under God, and seeks to impose its own D. on fellow men, in place of God's rule; 1267 AQUINAS (PE, p. 39) Someone is under the $\mathrm{D}$. of someone else as a slave when the lord controls him for his own benefit; 1324 MARSILIUS (DP, p. 4) But when discord and strife arose among them, their state was sorely beset by all kinds of hardships and troubles and underwent the $\mathrm{D}$. of hateful foreign nations; 1519 MACHIAVELLI (DTL, p. 116) Consequently the latter will be more keen on liberty since their hope of usurping D. over others will be less than in the case of the upper class.

(B) Control over territory 425 AUGUSTINE (CG, p. 138) And therefore it is beneficial that the good should extend their D. far and wide, and that their reign should endure, with the worship of the true God by genuine sacrifices and upright lives; 1519 MACHIAVELLI (DTL, p. 134) After them in the order of the celebrates are ranked the army commanders who have added to the extent of their own D.s or to that of their country's.

(C) having a position of guidance 1267 AQUINAS (PE, p. 39) However, someone can have D. over another person as a free man, when he directs him to his own good or to the good of the community.

\section{NOTES:}

Note that in (A) dominion is considered by all the authors as a negative thing, indicating Dominance and Slavery more than simple rule. Dominion over territory, however, is considered noble and good.

See: DUTY, KINGDOM, COMMONWEALTH, EMPEROR

\section{Duty}

(A) a formally enforced responsibility 425 AUGUSTINE (CG, p. 876) But until that home is reached, the fathers have an obligation 
to exercise the authority of masters greater than the D. of slaves to put up with their conditions as servants; 1324 MARSILIUS (DP, p. 57): For in those aspects which have been determined by law, the ruler's D. is to follow that legal determination.

(B) a formally unenforced social obligation 425 AUGUSTINE (CG, p. 860): Obviously, he will sit [on the judge's bench]; for the claims of human society constrain him and draw him to this D.; and it is unthinkable to him that he should shirk it; 1324 MARSILIUS (DP, pp. 10-11) ... because thus it seemed appropriate to all by a certain equity, not as a result of pro- longed inquiry, but solely by the common dictate of reason and a certain $\mathrm{D}$. of human society.

Notes:

Notice that duty has the connotation we might have expected from dominion. It is perhaps possible that Augustine prefers duty to dominion because of his fundamental distrust of humankind's impulses. He likely feels that men and women are unlikely to have the self-control described by Aquinas in Dominion $(\mathrm{C})$, and that if any good is to come of them, men and women must feel a sense of obligation, rather than empowerment.

See: VIRTUE

\section{Notes}

1. Much of my discussion here follows Ian Hacking's "Five Parables," in Philosophy in History, ed. Richard Rorty, J. B. Schneewind, and Quentin Skinner (Cambridge, England; Cambridge University Press, 1984), pp. 103-125, esp. 110-114. While, like Hacking, I am deeply suspicious of a problems approach to the study of philosophy, I also agree that the analytic skills gained by mastering this methodology can be valuable not as ends in themselves, but as means to other, more illuminating, intellectual projects to which the problems approach may be irrelevant.

\section{About the Author}

Darius Rejali teaches political philosophy and comparative politics at Reed College. $\mathrm{He}$ is the author of Torture and Modernity (Westview Press, 1994).

\title{
Iron Triangle Simulation: A Role-Playing Game for Undergraduates in Congress, Interest Groups, and Public Policy Classes
}

\author{
James W. Endersby and David J. Webber, University of Missouri-Columbia
}

D uring the winter semester of 1994, 130 students in three upperdivision undergraduate classes at the University of Missouri participated in a role-playing simulation of public policy formation in the U.S. Congress. This semester-long simulation enabled students to take a more active role in the learning process and to participate in an experience more closely resembling the real world of policy making.

This simulation involved three courses (Congress and Legislative Policy; Interest Group Politics; and Public Policy) taught by the two authors. Each of the authors independently reached the conclusion that the traditional lecture format in American politics courses often is not effective in providing students with an adequate understanding of the process underlying democratic decision making. High school civics and the evening news socialize undergraduates toward a passive study of political institutions. But the interaction and dynamic compromise inherent in the development of public policy can be lost using teaching strategies in which an instructor merely describes this dynamic relationship to students.

\section{Objectives and Structure of the Simulation}

Both instructors had employed role-playing simulations in previous courses but found that a political game lasting an hour or a week does not adequately provide students with the depth of knowledge obtainable in a lengthy simulation. Additionally, they believed that the relatively small scale of single-class simulations does not adequately reflect the uncertainty and complexity of the Washington environment. An alternative role-playing game was devised to introduce students to the process of politics. The goals of the simulation were to teach students how to cope with ill defined policy problems; to deal with a group policy-making process; and to improve written, oral, and electronic communication skills. Further, the instructors wanted to structure the simulation so that students still received much of the material presented in a more traditional course format, and they preferred that students would be graded on individual projects undertaken in a group process. Three contemporary public policy issues (environment, health care, and technology) were selected as the substantive policy focus for each of the three classes. The instructors coordinated their class schedules so that students could play their roles and interact with members of the other classes. Table 1 outlines the calendar for the three-course simulation.

Each student selected a role to play, subject to approval by the instructor. Students in the Congress class selected a House mem- 